\title{
Glimate change and the Arctic hydrologic cycle as calculated by a global coupled atmosphere-ocean model
}

\author{
JAMES R. MiLleR \\ Department of Marine and Coastal Sciences, Cook College, Rutgers University, New Brunswick, NJ 08903, U.S.A. \\ GARY L. Russell \\ NASA/Goddard Space Flight Center, Institute for Space Studies, 2880 Broadway, New Tork, N1 10025, U.S.A.
}

\begin{abstract}
A global coupled atmosphere-ocean model is used to examine the hydrologic cycle of the Arctic Ocean. The model has a horizontal resolution of $4^{\circ} \times 5^{\circ}$, nine vertical layers in the atmosphere and 13 in the ocean. River discharge into the Arctic Ocean is included by allowing runoff from each continental grid box to flow downstream according to a specified direction file and a speed that depends on topography. A 74 year control simulation of the present climate is used to examine variability of the hydrologic cycle, including precipitation, sea ice, glacial ice and river discharge. A 74 year transient simulation in which atmospheric $\mathrm{CO}_{2}$ increases each year at a compound rate of $1 \%$ is then used to examine potential changes in the hydrologic cycle. Among these changes are a $4 . \mathrm{C}$ increase in mean annual surface air temperature in the Arctic Ocean, a decrease in ice cover which begins after 35 years, and increases in river discharge and cloud cover. There is little change in the net difference between precipitation and evaporation. Also in the transient simulation, glacial ice on Greenland decreases relative to the control.
\end{abstract}

\section{INTRODUCTION}

Complex interactions between the ocean and atmosphere through the hydrologic cycle may be particularly sensitive to climate change in high northern latitudes because of the presence of sea ice. Recent concerns about climate change have led to the development of global climate models which can simulate past, present and future climates. Many studies have used atmospheric models with crude assumptions about the ocean which is a critical component of the climate system and must be incorporated fully into climate models.

There are a number of important issues in the development of coupled atmosphere ocean models. Among these are questions related to synchronous or asynchronous coupling because of the different time-scales of atmospheric and ocean models; the use of flux corrections to prevent the ocean model from drifting to a new climatic state; grid resolution; and the use of regional versus global models. Manabe and others (1991) used asynchronous coupling with flux corrections of heat and fresh water to prevent the coupled model from drifting to an unrealistic climate. Washington and Meehl (1989) did simulations without flux corrections but focused on shorter time-scales of decades to a century and assumed that any important climate signals would dominate the slow climate drift of the model. Both approaches are valid depending on the type of experiments to be examined. In this study, the second approach is taken because we are interested in timescales of less than a century.
Arctic and sub-Arctic regions are of great importance to climate studies. Ice provides a major feed-back in the climate system. Convection in the North Atlantic is one of the major driving forces in ocean circulation. The "great salinity anomaly" has caught the attention of many people due to its effect and possible implications on climate Dickson and others, 1988; Mysak and others, 1990). Potential changes in precipitation, evaporation and river flow can affect convection, ice formation and salinity. In this paper, a global coupled atmosphere ocean model is used to examine these potential changes.

\section{THE COUPLED ATMOSPHERE-OCEAN MODEL}

A coupled global atmosphere ocean model is used in this study. The resolution is $4^{\circ}$ latitude $\times 5^{\circ}$ longitude for the horizontal and 9 vertical layers in the atmosphere and 13 in the ocean. The atmosphere and ocean models are coupled synchronously every hour. A brief description of the model is given here. A more complete description is available from the authors upon request.

The physics source terms of the atmospheric model are similar to those of Hansen and others (1983). The atmospheric model includes the C-Grid scheme of Arakawa and Lamb (1977) to solve the momentum equation and Russell and Lerner's (1981) linear upstream scheme to advect potential enthalpy and water vapor. All significant atmospheric gases and aerosols are used to 
calculate the radiative source term. The model calculates runoff which is added to river systems that allow water to move between grid boxes and to the ocean according to the method of Miller and others (1994).

The ocean model has a free surface, uses the linear upstream scheme of Russell and Lerner (1981) for the advection of heat and salt, and solves the mass and momentum equations with a new C-Grid scheme. The model also calculates the flow of mass, potential enthalpy and salt through 12 straits which are too narrow to be resolved by the grid resolution. Fresh water is added directly to the ocean by precipitation or river flow.

For this paper the ocean model includes the thermodynamics of ice formation but does not allow for the horizontal advection of sea ice. In the model, $0.5 \mathrm{~m}$ thick sea ice forms horizontally when the open ocean attempts to cool below the freezing point. Sea ice thickens when excess snow is compacted into ice or when the water below the ice attempts to cool below the freezing point. Sea ice melts both horizontally and vertically with equal fractional reductions when the first ocean layer attempts to warm above $0^{\circ} \mathrm{C}$.

The purpose of this study is to examine components of the hydrologic cycle in the Arctic Ocean and potential changes associated with increasing levels of atmospheric greenhouse gases. In the model the Arctic Ocean is defined as all ocean area north of $68^{\circ} \mathrm{N}$, including the Greenland, Iceland, Norwegian (GIN) Sea, and its total area is $12.4 \times 10^{6} \mathrm{~km}^{2}$. The analysis is based on two 74 year simulations with the coupled atmosphere-ocean model, a control simulation for the present climate and a transient simulation in which atmospheric $\mathrm{CO}_{2}$ increases at a compound rate of $1 \%$ each year. No flux corrections are used. The initial conditions for each simulation were the final state of a 23 year integration that started from Levitus's (1982) temperature and salinity conditions.

\section{CHANGES IN FRESH-WATER INPUT}

The fresh-water budget of the Arctic Ocean depends on precipitation, river flow and the advection of sea ice. Fresh water is removed from the Arctic by the advection of sea ice, a mechanism which is not included in the model simulations here. According to Aagaard and Carmack (1989), approximately $2790 \mathrm{~km}^{3}$ of fresh water moves through the Fram Strait into the GIN Sea each year. Figure 1 shows the annual cycle of the model precipitation as compared to the observed. The model reproduces the summer maximum and winter minimum but generates too much precipitation in all months. It is in better agreement with Legates and Willmott (1990) than it is with Shea (1986).

Figure 2 shows changes in the annual precipitation during the 74 year simulations. The variability is approximately $10 \%$ of the mean and shows no long-term trend. Although there is evidence of a 30-35 year cycle between periods of higher and lower precipitation for the present climate, it might not recur in a longer simulation.

The net water flux at the air/sea interface depends on the difference between precipitation and evaporation. Figure 3 shows that the annual net water flux increases for both the control and transient simulations during the 74

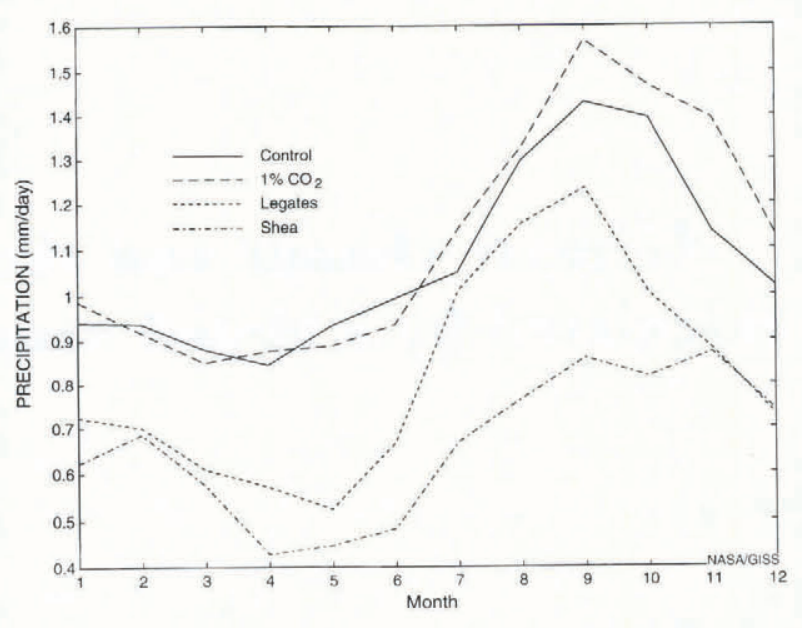

Fig. 1. Monthly precipitation in the Arctic Ocean for the last 10 years of the control and transient simulations compared with the observations of Legates and Willmotl (1990) and Shea (1986).

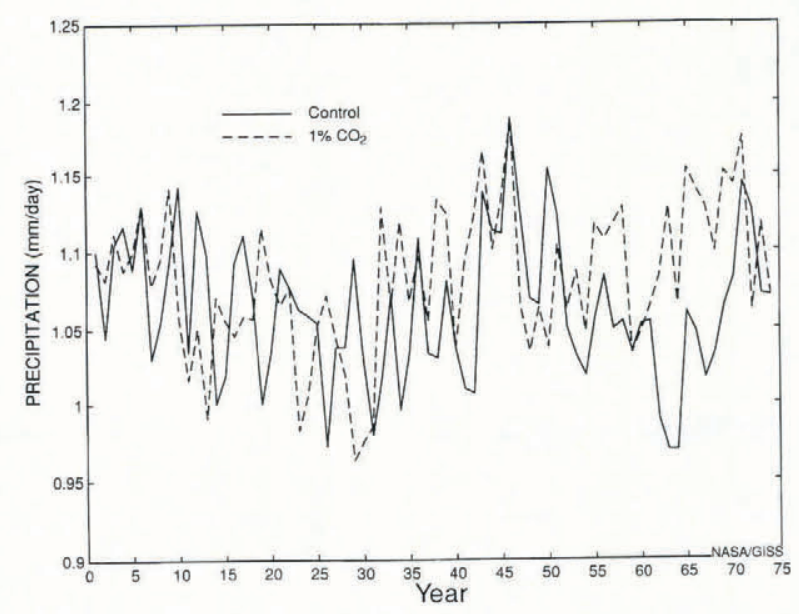

Fig. 2. Temporal variation of annual precipitation in the Arctic Ocean for the control and transient simulations.

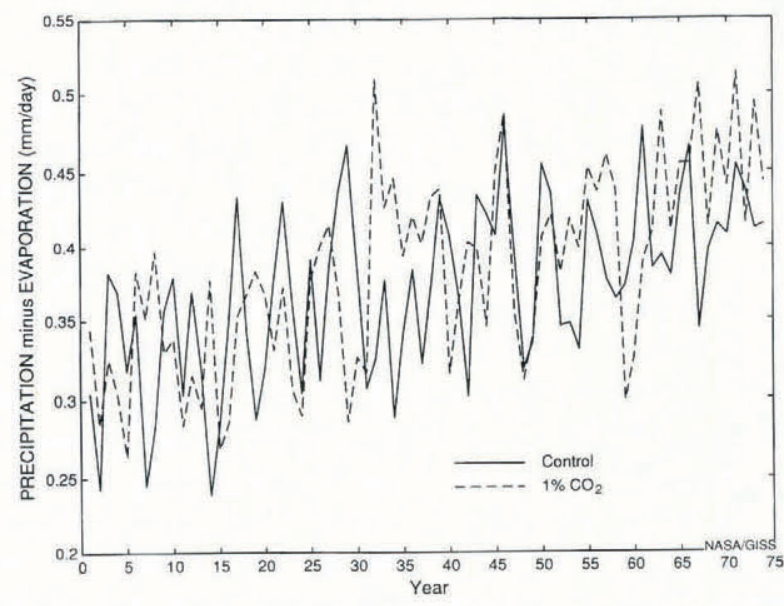

Fig. 3. Temporal variation of the annual difference between precipitation and evaporation in the Arctic Ocean for the control and transient simulations. 


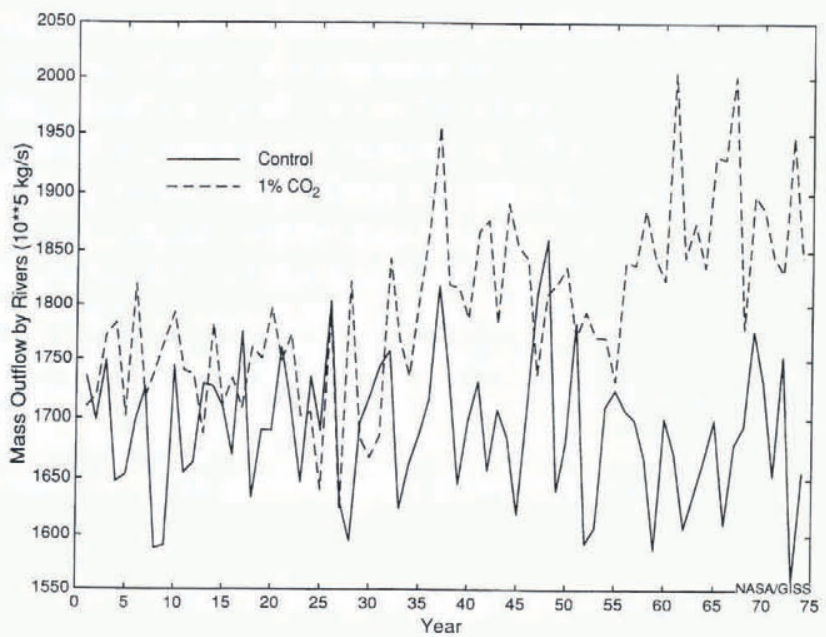

Fig. 4. Temporal variation of annual river flow into the Arctic Ocean for the control and transient simulations.

year period. Since there was little long-term trend in precipitation, there must be a long-term decrease in evaporation for the control and transient simulations. The reasons for this are discussed in section 5. Although one must be somewhat careful in drawing conclusions based on a model that includes such a trend, the results indicate that there is no significant change in the net precipitation minus evaporation between the control and transient simulations.

River flow is another component of the water budget in the Arctic. In a previous study of a doubled $\mathrm{CO}_{2}$ climate, Miller and Russell (1992) found that there was an increase in river flow into the Arctic Ocean. Figure 4 shows that river flow also increases in the transient run. When the river flow is combined with the precipitation and evaporation, there is a net increase in fresh-water input into the Arctic Ocean in the transient experiment compared to the control.

The water flux into the Arctic Ocean affects the surface salinity. Although the annual variation of the model sea-surface salinity is in phase with the observed, there is a long-term decrease of $1 \%$ in the model surface salinity during both the control and transient simulations. This is due to several factors including the lack of ice advection to remove fresh water from the Arctic, the increasing trend in precipitation minus evaporation, and the excess river flow into the Arctic Ocean.

Clouds are closely linked with the global hydrologic cycle. Figure 5 shows that the mean annual cloud cover increases during the transient simulation. In both simulations cloud cover varies seasonally with a maximum of $85 \%$ in summer. The principal change occurs in the winter as the cloud cover increases from $50 \%$ to $60 \%$ in the transient simulation.

\section{GHANGES IN SEA ICE AND GLACIAL ICE}

Ice provides important climate feed-backs at high latitudes. When the climate warms locally, both the thickness and horizontal extent of sea ice decrease. This allows more absorption of solar radiation which in turn further warms the climate.

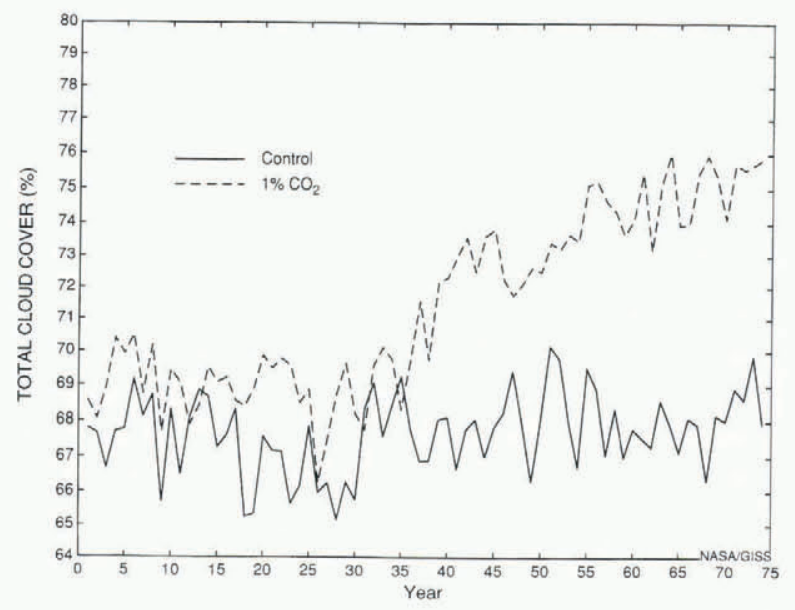

Fig. 5. Temporal variation of annual total cloud cover in the Arctic Ocean for the control and transient simulations.

A major factor that affects ice formation and melting is surface air temperature. Figure 6 shows the variation of annual surface air temperature in the Arctic Ocean for the control and transient simulations. Although the average temperatures in the Arctic increase by nearly $4{ }^{\circ} \mathrm{C}$ by the end of the simulation, there are also significant temporal and spatial variations. The surface air temperature is $6^{\circ} \mathrm{C}$ warmer in the winter and only about $1^{\circ} \mathrm{C}$ warmer in the summer. The average surface air temperature decreases by

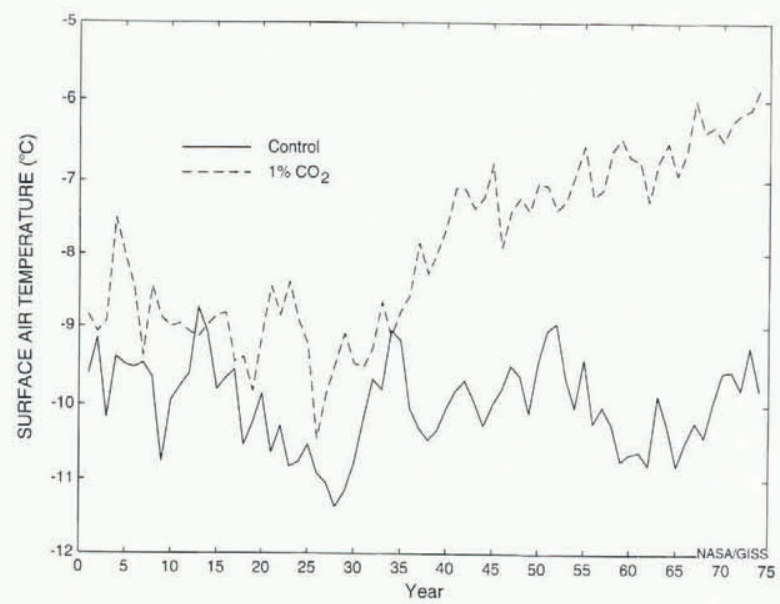

Fig. 6. Temporal variation of annual surface air temperature in the Arctic Ocean for the control and transient simulations.

more than $4^{\circ} \mathrm{C}$ in the Barents and GIN Sea regions and increases by more than $6^{\circ} \mathrm{C}$ in most of the rest of the Arctic Ocean. The higher winter air temperatures are consistent with the higher winter cloud cover discussed in the previous section. It should also be noted that in the transient simulations of Hansen and others (1988) in which ocean heat transports were specified at constant values, such regions of cooling did not exist. The cooling is related to changes in ocean dynamics, including reduced transports of heat by the ocean into the region.

Figure 7 shows the comparison of the model's monthly 


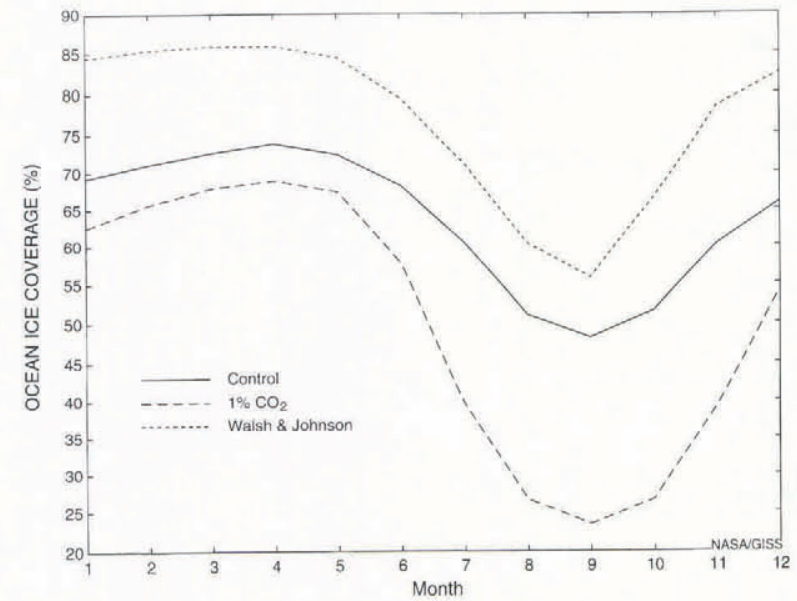

Fig. 7. Monthly ocean ice cover in the Arctic Ocean for the last 10 years of the control and transient simulations compared with the observations of Walsh and Johnson (1979).

climatology of ice cover for the last 10 years of each simulation with the observations of Walsh and Johnson (1979). The model reproduces the annual cycle except that it is $10-15 \%$ too low compared to the observations. One problem in the simulation is that most of the sea ice in the GIN Sea has melted in the control run. The ice cover is significantly reduced for the transient simulation. The effect is particularly pronounced in the summer where the ice cover is reduced by about half.

Figure 8 shows the annual ocean ice cover during the 74 year simulations. For the present climate there is a small increasing trend with cyclic variations. The two periods of maximum ice cover at years 25 and 60 correspond to the periods of minimum precipitation shown in Figure 2. The transient simulation changes similarly to the control run for the first 35 years, after which the ice cover continues to decrease. At the end of the transient simulation, the mean annual area of the Arctic covered by ice has decreased from approximately $60 \%$ to $50 \%$.

In addition to sea ice, glacial ice is likely to respond to climatic change. A critical question is whether increased

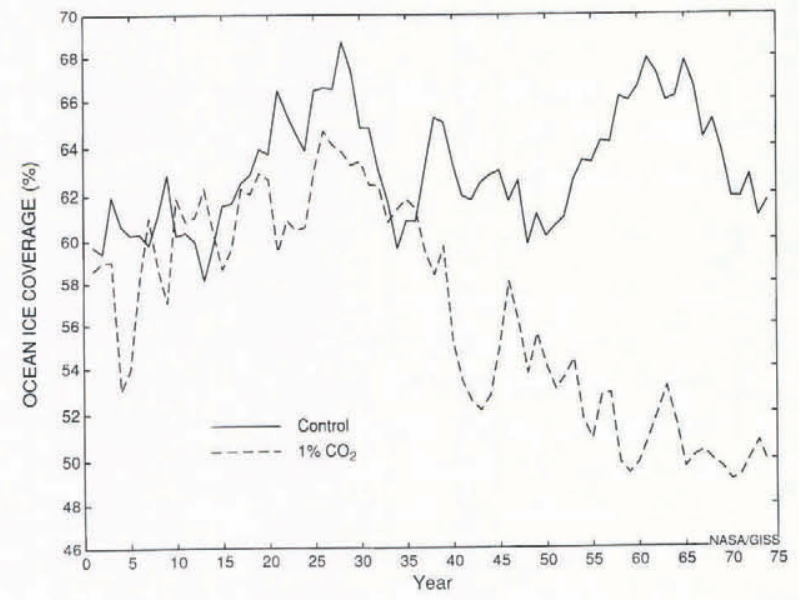

Fig. 8. Temporal variation of annual ocean ice cover in the Arctic Ocean for the control and transient simulations. temperatures will lead to a net decrease in glacial volume or to increased snow and subsequent growth of glaciers. Melting glaciers would lead to increasing sea levels and would have significant impact on human activities. Figure 9 shows the difference between the annual glacial ice growth of the transient and control simulations. In both hemispheres there is a net reduction of land ice in the transient simulation relative to the control. The interannual variability of land ice is higher in the Northern Hemisphere. Relative to the control there is slightly more ice accumulation in the Antarctic interior in the transient experiment but significantly more melting near the edges.

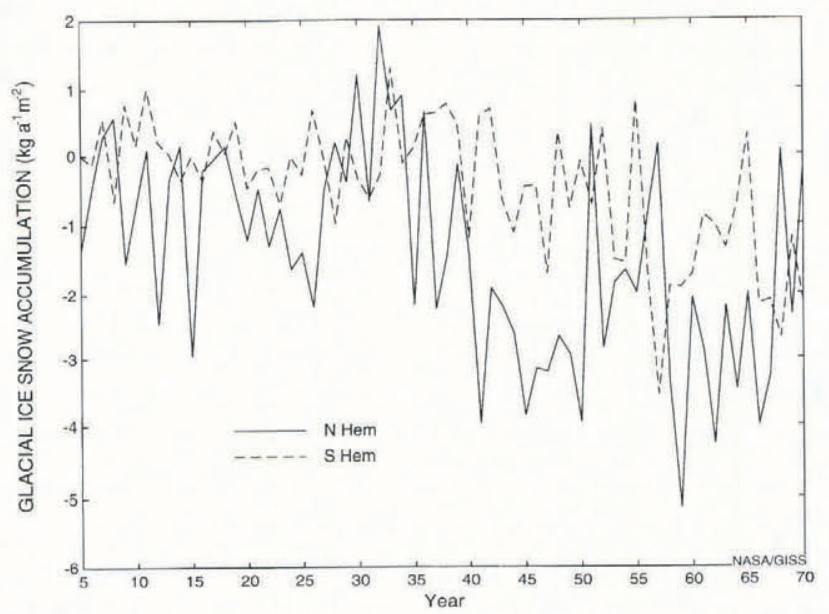

Fig. 9. Temporal variation of the net glacial ice accumulation for the transient experiment minus the control. The control is based on a 9 year average so that the inter-annual variability of the transient experiment is represented in the graph.

\section{DISCUSSION}

One of the major goals of climate modeling is the development of models that are sufficiently realistic to be able to predict future climatic change in response to increases of atmospheric greenhouse gases. Although coupled atmosphere ocean models are still being improved, it is possible to examine climate-change scenarios now and learn how the present generation of climate models respond to such changes. The insights from such studies improve our understanding of the climate system and its variability.

In this study, potential changes in the hydrologic cycle of the Arctic Ocean are examined using 74 year simulations, a control for the present climate and a transient experiment in which atmospheric $\mathrm{CO}_{2}$ levels increase at a compound rate of $1 \%$ per year. The latter corresponds to a doubling of $\mathrm{CO}_{2}$ at year 70. Although the model surface salinity is not in steady state for the present climate, a number of interesting results emerge. The decrease in ocean ice cover in the transient simulation does not become apparent until after year 35. This begins at the same time that the cloud cover starts to increase.

Although the results of this study show that there are climatic changes in the Arctic Ocean in response to 
increasing $\mathrm{CO}_{2}$ levels, the changes in precipitation and the net water flux (precipitation minus evaporation) are increasing at a similar rate in both the control and transient simulations. This is primarily because the evaporation is decreasing in both the control and transient simulations. In the control this decrease appears to be associated with an increase in ice cover that reduces evaporation by reducing the area of open ocean. In the transient case the reason for the decrease, which is of the same order in summer and winter, is more complex. Decreased evaporation in the transient case is due primarily to the decreased sea-surface temperatures (SSTs) in the GIN and Barents Seas. Since SSTs in these regions are much higher than in the rest of the Arctic and since evaporation is a non-linear function of temperature, the increased evaporation in the rest of the Arctic due to less sea ice and warmer SSTs is not sufficent to outweigh the decreased evaporation in the GIN and Barents Seas. SSTs decrease in these regions for at least two reasons associated with ocean dynamics. First, convection is reduced, which reduces the amount of sub-surface warmer water that is mixed into the surface layer. Secondly, the northward transport of heat into the GIN Sea decreases in the transient simulation.

Other changes that occur in the transient simulation are that the thickness and horizontal extent of sea ice decrease in the transient experiment, while air temperature, cloud cover and river discharge increase. The absence of sea-ice advection in the model and the decreasing trends in evaporation and sea-surface salinity make it harder to draw firm conclusions from the simulations. The complex nature of interactions among different components of the climate system at high latitudes do indicate that only by using coupled atmosphere-ocean ice models can one expect to include the important feed-backs which occur.

\section{ACKNOWLEDGEMENTS}

We would like to thank G. Caliri for helping to prepare the figures for this paper and S. Howard for helping to analyze results from a previous version of the model. Partial support for the first author has been provided under Project No. 32103 of the New Jersey Agricultural Experiment Station.

\section{REFERENCES}

Aagaard, K. and E. C. Carmack, 1989. The role of sea ice and other fresh waters in the Arctic circulation. J. Geophys. Res., 94 C10), 14,485-14,498.

Arakawa, A. and V.R. Lamb. 1977. Computational design of the basic dynamical processes of the UCLA general circulation model. Methods Compul, Phys., 17.

Dickson, R. R., J. Meincke, S. A. Malmberg and A.J. Lee. 1988. The "great salinity anomaly" in the northern North Atlantic 1968-1982. Prog. Oceanogr., 20, 103-151.

Hansen, J. and 7 others. 1983. Eflicient three-dimensional global models for climatic studies: models I and II. Mon. Weather Rev., 111, 609-662.

Hansen, J. and 7 others. 1988. Global climate changes as forecast by Goddard Institute for Space Studies three-dimensional model. \% Geophys. Res., 93 D8), 9341-9364.

Legates, D. and C. Willmott. 1990. Mean seasonal and spatial variability in gauge-corrected global precipitation. Int. J. Climatol., 10, $111-128$.

Levitus, S. 1982. Climatological allas of the world ocean. Washington, DC, National Oceanographic and Atmospheric Administration. Professional Paper 13.)

Manabe, S., R.J. Stouffer, M.J. Spelman and K. Bryan. 1991. Transient responses of a coupled ocean-atmosphere model to gradual changes of atmospheric $\mathrm{CO}_{2}$. Part I: Annual mean response. J. Climate, 4, 785817.

Miller, J. R. and G. L. Russell. 1992. The impact of global warming on river runoff. J. Geophys. Res., 97 (D3), 2757-2764.

Miller, J. R., G. L. Russell and G. Caliri. 1994. Continental scale river flow in climate models. J. Climate, 7, 914928.

Mysak, L. A., D. K. Manak and R. F, Marsden. 1990. Sea-ice anomalies observed in the Greenland and Labrador seas during 1901-1984 and their relation to an interdecadal Arctic climate cycle. Climate Dyn., 5 2), $111-133$.

Russell, G. L. and J.A. Lerner. 1981. A new finite-differencing scheme for the tracer transport equation. J. Appl. Meteorol., 20, 1483-1498.

Shea, D. 1986. Climatological allas: 1950-1979 Surface air temperature, precipitation. sea-level pressure and sea-surface temperature $\left(45^{\circ} \mathrm{S} 90^{\circ} \mathrm{N}\right)$. Boulder, CO, National Center for Atmospheric Research.

Walsh, J.E. and C. M. Johnson. 1979. An analysis of Arctic sea ice fluctuations, 1953-77. J. Phys. Oceanogr., 9 (3), 580-591.

Washington, W. M. and G. A. Meehl. 1989. Climate sensitivity due to increased $\mathrm{CO}_{2}$ : experiments with a coupled atmosphere and ocean general circulation model. Climate Dyn., 4, 1-38. 